\title{
Dual-targeted hybrid nanoparticles of synergistic drugs for treating lung metastases of triple negative breast cancer in mice
}

\author{
Tian ZHANG ${ }^{1, \#}$, Preethy PRASAD ${ }^{1, \#}$, Ping CAI ${ }^{1}$, Chunsheng $\mathrm{HE}^{1}$, Dan $\mathrm{SHAN}^{1}$, Andrew Michael RAUTH${ }^{2}$, Xiao Yu WU ${ }^{1, *}$ \\ ${ }^{1}$ Advanced Pharmaceutics and Drug Delivery Laboratory, Leslie Dan Faculty of Pharmacy, University of Toronto, Toronto, Ontario, \\ Canada M5S 3M2; ' ${ }^{2}$ Departments of Medical Biophysics and Radiation Oncology, University of Toronto, Toronto, Ontario, Canada M5G \\ $2 M 9$
}

\begin{abstract}
Lung metastasis is the major cause of death in patients with triple negative breast cancer (TNBC), an aggressive subtype of breast cancer with no effective therapy at present. It has been proposed that dual-targeted therapy, ie, targeting chemotherapeutic agents to both tumor vasculature and cancer cells, may offer some advantages. The present work was aimed to develop a dual-targeted synergistic drug combination nanomedicine for the treatment of lung metastases of TNBC. Thus, Arg-Gly-Asp peptide (RGD)conjugated, doxorubicin (DOX) and mitomycin C (MMC) co-loaded polymer-lipid hybrid nanoparticles (RGD-DMPLN) were prepared and characterized. The synergism between DOX and MMC and the effect of RGD-DMPLN on cell morphology and cell viability were evaluated in human MDA-MB-231 cells in vitro. The optimal RGD density on nanoparticles (NPs) was identified based on the biodistribution and tumor accumulation of the NPs in a murine lung metastatic model of MDA-MB-231 cells. The microscopic distribution of RGD-conjugated NPs in lung metastases was examined using confocal microscopy. The anticancer efficacy of RGDDMPLN was investigated in the lung metastatic model. A synergistic ratio of DOX and MMC was found in the MDA-MB-231 human TNBC cells. RGD-DMPLN induced morphological changes and enhanced cytotoxicity in vitro. NPs with a median RGD density showed the highest accumulation in lung metastases by targeting both tumor vasculature and cancer cells. Compared to free drugs, RGD-DMPLN exhibited significantly low toxicity to the host, liver and heart. Compared to non-targeted DMPLN or free drugs, administration of RGD-DMPLN (10 mg/kg, iv) resulted in a 4.7-fold and 31-fold reduction in the burden of lung metastases measured by bioluminescence imaging, a 2.4-fold and 4.0-fold reduction in the lung metastasis area index, and a $35 \%$ and $57 \%$ longer median survival time, respectively. Dual-targeted RGD-DMPLN, with optimal RGD density, significantly inhibited the progression of lung metastasis and extended host survival.
\end{abstract}

Keywords: polymer-lipid hybrid nanoparticles; triple negative breast cancer; human MDA-MB-231 cells; lung metastases; doxorubicin; mitomycin C; synergistic action; dual-targeted; RGD

Acta Pharmacologica Sinica (2017) 38: 835-847; doi: 10.1038/aps.2016.166; published online Feb 202017

\section{Introduction}

Breast cancer is the most common cancer and the leading cause of cancer death in women worldwide. Among the various subtypes of breast cancer, approximately $15 \%-20 \%$ belong to triple negative breast cancer $(\mathrm{TNBC})^{[1]}$. Given a lack of estrogen receptor, progesterone receptor, and human epidermal growth factor receptor 2 (HER2), targeted therapies for breast cancer, such as trastuzumab and tamoxifen, are not effective for $\mathrm{TNBC}^{[1-4]}$. Therefore, chemotherapy remains the

\footnotetext{
\#These authors contributed equally to this work.

${ }^{*}$ To whom correspondence should be addressed.

E-mail xywu@phm.utoronto.ca

Received 2016-11-09 Accepted 2016-12-26
}

main therapeutic option for TNBC patients in the neoadjuvant, adjuvant or metastatic settings ${ }^{[5-7]}$. Among various neoadjuvant and adjuvant regimens, anthracycline-taxane chemotherapy represents a commonly used regimen, which results in a pathologic complete response rate $(\sim 30 \%)$ that is higher than other combination regimens; however, relapse frequently occurs leading to short survival times ${ }^{[7-9]}$. Recently, antiTrop-2 antibody-SN-32 conjugate (IMMU-132), which targets the protein Trop-2 that is highly expressed in many cancers, including $>90 \%$ of TNBC, has been investigated in clinical trials $^{[10]}$. The results from initial Phase I/II trials are promising; however, the objective response rate $(33 \%)$ in pretreated metastatic TNBC patients is similar to standard chemotherapy alone $^{[11,12]}$. This relatively low response rate might be due to 
the heterogeneity of TNBC, in which six molecular subtypes have recently been identified that respond differently to the treatments ${ }^{[13,14]}$. Thus, dual-targeted therapy, ie, targeting chemotherapeutic agents to both tumor vasculature and cancer cells, may offer some advantages.

Targeting av $\beta 3$ integrin that is overexpressed in invasive breast cancer cells and angiogenic endothelium of tumor vasculature has been explored as integrins play important roles in tumor growth, metastasis, and drug resistance as well as tumor angiogenesis ${ }^{[15-21]}$. Moreover, an "angiogenic switch" occurs in endothelial cells, near tumor cells, at an early stage of tumor development ${ }^{[22]}$. Peptide ligands such as Cilengitide, an Arg-Gly-Asp (RGD) peptide mimetic, have been investigated as av integrin-targeted therapies; however, the results from advanced clinical trials were negative, which might be due to the short half-life of the compounds in vivo and insufficient compound reaching tumor cells ${ }^{[23]}$. In contrast to free integrin-binding peptides, which rely on their direct cytotoxic effect, RGD-conjugated nanoparticle (NP) systems can actively deliver loaded drugs to integrin-overexpressing tumor vasculature and cancer cells. Targeting av $\beta 3$ integrin is currently being explored by various research groups with different NP systems to improve diagnostic imaging ${ }^{[24-26]}$ as well as to enhance the delivery of anti-cancer agents to tumors ${ }^{[27-30]}$. Though some targeted therapeutic NP systems demonstrated better efficacy against cancers compared to non-targeted NPs, testing the role of ligand density on tumor uptake and antitumor activity was often neglected ${ }^{[31]}$.

Previously, we developed cyclic RGD peptide functionalized solid lipid NPs (RGD-SLN) that target av $\beta 3$-overexpressing TNBC tumors ${ }^{[32]}$. By testing the SLN with different RGD content, the RGD-SLN with a low RGD content was found to accumulate in primary TNBC tumors by avoiding extensive hepatic uptake ${ }^{[33]}$. Because the biology of the primary tumor and the lungs is different, the optimal RGD density needed to be re-evaluated to target the lung metastasis where av $\beta 3$ integrin-overexpressing tumor neovasculature and TNBC cells coexist $^{[34]}$. For treatment of lung metastases of TNBC, we have co-encapsulated doxorubicin (DOX) and mitomycin C (MMC) in the stealth polymer-lipid nanoparticle (PLN), at a synergistic ratio that enhanced cytotoxicity in both sensitive and multi-drug resistant (MDR) breast cancer cells ${ }^{[35-39]}$. This combination of DOX and MMC has also shown elevated efficacy against solid tumors in murine models ${ }^{[39-43]}$. Furthermore, since a majority of TNBC tumors are found to have mutated DNA damage-repair genes, including TP53 and BRCA, the genetically unstable TNBC cells might be more susceptible to DNA-interfering chemotherapeutic agents ${ }^{[44-46]}$. Thus, the DOX and MMC combination that significantly increased DNA cross-linking and double-strand breaks ${ }^{[36]}$ may be highly cytotoxic to MDA-MB-231 TNBC cells, which are mutated in the TP53 gene ${ }^{[47]}$.

Metastasis of breast cancer from the primary tumor site to a distant site, eg, the lungs, is the major cause of death in TNBC patients ${ }^{[3]}$. Metastasis is a multi-step process that involves tumor cell migration from the primary tumor, intravasation, survival during circulation, extravasation from the circulatory system, and colonization at a distant site ${ }^{[48]}$. In the present study, we established an experimental lung metastasis mouse model of TNBC by intravenous (iv) injection of a highly aggressive metastatic human TNBC cell line, MDA-MB-231luc-D3H2LN ${ }^{[49]}$, which partially resembles the real metastatic process from circulating cancer cells. This metastatic model provides the advantages of rapid model maturity, consistent and reproducible metastasis and control over the number of cells injected into each mouse, and it is widely adopted for preclinical evaluation of various therapeutic formulations ${ }^{[50]}$.

The present work was aimed to prepare and evaluate a dual-targeted, DOX and MMC co-loaded PLN (DMPLN) formulation with optimal RGD content to inhibit the growth of lung metastases of TNBC. Synergism between DOX and MMC was evaluated. RGD-conjugated NPs were investigated in vitro for their cytotoxicity and effect on cellular morphology. Then, these formulations were tested in vivo to determine the optimal RGD density for maximum NP accumulation in metastasis-bearing lungs. RGD-conjugated DMPLN (RGDDMPLN) with the optimal RGD density were further evaluated for their in vivo efficacy against lung metastases of TNBC, as determined by tumor bioluminescence, mouse survival, lung weight, and H\&E stained metastatic lung nodules. Dosedependent toxicity of RGD-DMPLN, DMPLN and free DOXMMC solution was also examined.

\section{Materials and methods}

Preparation and characterization of polymer-lipid nanoparticles The targeting conjugate Myrj59-cRGDfK and the NPs were prepared and characterized as previously described ${ }^{[32,33,39]}$. Indocyanine green (ICG)-loaded PLN and RGD-DMPLN were similarly prepared with minor modifications. Particle size and zeta potential were measured with Malvern Zetasizer Nano ZS (Worcestershire, UK). The DMPLN suspension was centrifuged through a $0.1 \mu \mathrm{m}$ filter unit to remove the encapsulated drugs. The molar ratio of DOX:MMC was determined. Drug encapsulation efficiency (EE) (\%wt-loaded drug/wt total drug) was then calculated in the filtrate. DMPLN were made fresh before each injection. The molar ratio of DOX and MMC is calculated based on:

$$
\text { Molar ratio }=\frac{m_{\text {Dox }} \times E_{\text {Dox }}}{M_{\text {Dox }}}: \frac{m_{M M C} \times E_{M M C}}{M_{M M C}}
$$

where $\mathrm{m}$ is the mass of DOX or MMC used in the formulation (DOX: $5 \mathrm{mg}$; MMC $4 \mathrm{mg}$ ), EE is the encapsulation efficiency of DOX or MMC, and M is the molecular weight of DOX (580.0 $\mathrm{g} / \mathrm{mol}$ ) or MMC (334.3 $\mathrm{g} / \mathrm{mol})$. The release profiles of DOX and MMC from RGD-DMPLN in phosphate-buffered saline was determined by a dialysis method. The detailed formulation and characterization methods are described in the Supplemental Materials.

\section{Quantification of RGD ligand on nanoparticles}

The amount of RGD on the RGD-PLN with various ligand densities was measured using a fluorometric technique 
adapted from the literature ${ }^{[51]}$. The number of RGD on the surface of each NP was estimated as previously described ${ }^{[33]}$ (See details in Supplementary Materials).

\section{Evaluation of DOX and MMC synergy}

A clonogenic assay was used to evaluate the synergism of DOX and MMC. MDA-MB-231 cells were plated in $6 \mathrm{~cm}$ culture dishes for $24 \mathrm{~h}$. After $1 \mathrm{~h}$ incubation with DOX and/or MMC, as single agents or in combination (DOX: MMC molar ratio $=1$ : 0.7 ) at DOX concentrations of $0.0005-20 \mu \mathrm{mol} / \mathrm{L}$, the cells were washed and trypsinized. The cells were replated at 500 cells per well in a 6-well plate and allowed to grow into colonies for $7 \mathrm{~d}$. The colonies were stained with a $0.5 \%$ solution of methylene blue in $70 \%$ ethanol and counted on a light table.

Median effect analysis was conducted as previously described $^{[35,39,52]}$. The median effect plot of $\log \left[\left(f_{a}\right)^{-1}-1\right]^{-1}$ versus $\log [\mathrm{D}]$ was generated for DOX alone, MMC alone and DOX/ MMC combination, where $f_{a}$ is the fraction of cells affected, and $\mathrm{D}$ is the drug concentration. The slope (m), a measure of sigmoidicity, and the median effect dose $\left(D_{m}\right)$ were determined from the fitted plot. The dose of the individual drugs and drug combination that affect a given percent $(x \%)$ of the plated colonies, $\mathrm{D}_{\mathrm{x} 1}, \mathrm{D}_{\mathrm{x} 2}$ and $\mathrm{D}_{\mathrm{x} 1,2}$, was calculated from $\mathrm{Eq} 2$ :

$$
D_{x}=D_{m}\left[\frac{f_{a}}{1-f_{a}}\right]^{1 / m}
$$

Based on Eq 2, the combination index (CI) was calculated from Eq 3:

$$
C I=\frac{D_{1}}{D_{x 1}}+\frac{D_{2}}{D_{x 2}}+\frac{D_{1} D_{2}}{D_{x 1} D_{x 2}}
$$

Values of $C I<1,=1$, and $>1$ indicate synergism, additive effect, and antagonism, respectively.

\section{In vitro cytotoxicity test}

Luciferase-transfected human TNBC MDA-MB-231-lucD3H2LN cells were plated in vitro on vitronectin-coated 96-well plates overnight for $18 \mathrm{~h}$. Cells were treated with the following formulations at $37^{\circ} \mathrm{C}$ and $5 \% \mathrm{CO}_{2}$ for $1 \mathrm{~h}$ : blank RGD-PLN with various RGD levels at seven PLN concentrations (0.139-695 mg/mL), DOX-MMC co-loaded PLN (RGDDMPLN and DMPLN) and free DOX and MMC at equivalent DOX concentrations of $0.01-50 \mathrm{mg} / \mathrm{mL}$. After the $1 \mathrm{~h}$ treatments, cells were washed twice with phosphate-buffered saline and incubated for $24 \mathrm{~h}$ in growth medium, and cell viability was measured with an ATP bioluminescence assay by adding $0.75 \mathrm{mg} / \mathrm{mL}$ of D-luciferin to each well. The bioluminescence intensity, a measure of cell viability (Figure S4), was immediately measured using a Xenogen IVIS Spectrum imager (Caliper Life Sciences, Inc, Hopkinton, MA, USA). A commonly used cell viability assay, using 3-(4,5-dimethylthiazol-2-yl)-2,5-diphenyltetrazolium bromide (MTT), was also performed for free DOX and MMC treatments under the same conditions to confirm the validity of the bioluminescence method.

\section{Lung metastasis model}

All animal handling and procedures were conducted under an approved protocol from the Animal Care Committee at the Ontario Cancer Institute. Female, SCID mice (6 weeks old) were injected with 0.5 million MDA-MB-231-luc-D3H2LN cells in $100 \mu \mathrm{L}$ of growth medium via the tail vein to establish lung metastases. Animals had ad libitum food and water and were maintained in Allentown ventilated microisolator cages (Allentown, NJ, USA). After 1 week, D-luciferin solution $(150 \mathrm{mg} / \mathrm{kg})$ was injected intraperitoneally into the mice, and bioluminescence images were obtained $10 \mathrm{~min}$ post injection using the Xenogen imager.

\section{Biodistribution study}

Two weeks after tumor inoculation in female SCID mice, PLN or RGD-PLN loaded with near infrared (NIR) dye ICG were injected into the lateral tail vein of mice. Biodistribution of the NPs was recorded at various time points with excitation and emission wavelengths of $745 \mathrm{~nm}$ and $820 \mathrm{~nm}$, respectively, using the Xenogen imager. In a separate experiment, mice were euthanized by $\mathrm{CO}_{2}$ asphyxiation after $4 \mathrm{~h}$, and the liver, spleen, kidneys, heart, and lungs were excised and immediately imaged with the imager. The fluorescence emitted was quantified with Living Image software over the region of interest (ROI).

\section{Microscopic examination of nanoparticle distribution in the lung metastasis}

Saline, fluorescein isothiocyanate (FITC)-labelled PLN and RGD-PLN were injected via the tail vein of the mice two weeks after tumor inoculation. The metastasis-bearing lungs were perfused and resected $4 \mathrm{~h}$ following treatment and quickly frozen in optimal cutting temperature compound with liquid nitrogen. Samples were preserved at $-80^{\circ} \mathrm{C}$ until sectioned and stained for nuclei with $4^{\prime}, 6$-diamidino-2-phenylindole (DAPI), for endothelial cells with Alexa Fluor ${ }^{\circledR}$ 647-labelled anti-CD-31 antibody and for metastatic nodules with H\&E. Images were acquired with an Olympus Upright Confocal Microscope (Richmond Hill, ON, Canada) and overlaid by ImageJ.

\section{Assessment of general, cardiac and hepatic toxicity}

One week after tumor inoculation treatments were initiated in the SCID mice, an initial test was conducted to determine the tolerable free DOX and MMC doses, as well as DMPLN and RGD-DMPLN doses, because DNA repair mechanisms in SCID mice are impaired ${ }^{[53]}$. Metastasis-bearing mice (5/ group, unless otherwise indicated) were randomly allocated to different treatment groups: (1-4) free drugs (3-15 mg/ kg), (5-8) DMPLN (3-15 mg/kg), and (9-12) RGD-DMPLN (3-15 $\mathrm{mg} / \mathrm{kg}, n=3)$. RGD-DMPLN with a medium ligand density were used. Each treatment was administered intravenously via the tail vein. The condition of each mouse was monitored every other day following treatment. The acute cardiac and hepatic toxicity were assessed on $\mathrm{d} 7$ post treatment using H\&E histopathological analysis, cardiac troponin I (cTnI) 
assay and alanine transaminase (ALT) assay. The detailed methods are presented in the Supplementary Materials.

\section{Evaluation of in vivo therapeutic efficacy}

One-week after tumor inoculation, mice were randomly allocated to different treatment groups: 1) saline $(n=4), 2)$ free DOX and MMC (3 mg/kg, $n=5), 3)$ RGD-DMPLN (3 mg/kg, $n=5), 4)$ DMPLN (10 mg/kg, $n=6)$, and 5) RGD-DMPLN (10 $\mathrm{mg} / \mathrm{kg}, n=6)$. The formulations were administered via tail vein injection. Tumor growth was monitored weekly by bioluminescence imaging with a $1 \mathrm{~min}$ exposure time $10 \mathrm{~min}$ after intraperitoneal injection of $D$-luciferin $(150 \mathrm{mg} / \mathrm{kg})$. The signal intensity of lung metastases was quantified as the sum of all detected photon counts within the ROI. The mice were continuously monitored to evaluate their survival time. In a separate set of experiments, metastasis-bearing mice were treated with 1) saline $(n=4), 2)$ free DOX and MMC (3 mg/ kg, $n=4)$, 3) RGD-DMPLN (10 mg/kg, $n=4)$, and 4) DMPLN (10 $\mathrm{mg} / \mathrm{kg}, n=4)$. On d 21 following the treatment, the mice were sacrificed and the resected lungs were imaged, weighed, and fixed in buffered formalin. The lungs were coronally sectioned three times and stained with H\&E. The dark purple metastatic nodules in the H\&E-stained lungs were quantified by a "metastasis area index," which was calculated as the ratio of metastasis area to total lung area. The area was analyzed using ImageJ software.

\section{Results}

\section{Properties of NPs and quantification of RGD content}

The prepared NPs had a particle size of 148-165 $\mathrm{nm}$ and zeta potential between $-18.5 \mathrm{mV}$ and $-32.4 \mathrm{mV}$ (Table S1). The drug encapsulation efficiency of DOX and MMC in various nanoparticle formulations was determined to be $92.3 \%-94.4 \%$ and $49.3 \%-51.5 \%$, respectively (Table S1). The DOX/MMC molar ratio was found to be $\sim 1: 0.7$ using Eq 1. The release of DOX and MMC from RGD-DMPLN (Med) was sustained with $\sim 40 \%$ of the payload being released in $72 \mathrm{~h}$ and exhibited similar kinetic profiles (Figure S1). The much slower drug release determined from the nanoparticle formulation than from the free solution (Figure S1) indicates that the nanocarrier, instead of the dialysis membrane, is indeed controlling the drug release rate ${ }^{[54]}$. The coating efficiency of each RGD-PLN formulation was determined to be $46 \%-50 \%$ (Table 1 ). The number of RGD ( $\mathrm{N}_{\mathrm{RGD}}$ ) on each particle was estimated as described in Supplemental Material S1.4: approximately 64 $\pm 24,593 \pm 108$,

Table 1. Quantification of the amount of RGD peptide on the PLN using 9,10-phenanthrenequinone. The data are represented as mean \pm SD. $n=3$.

\begin{tabular}{lcc}
\hline $\begin{array}{c}\text { RGD-PLN } \\
\text { (RGD feed concentration) }\end{array}$ & $\begin{array}{c}\text { RGD concentration } \\
\text { detected }(\mu \mathrm{mol} / \mathrm{L})\end{array}$ & $\begin{array}{c}\text { RGD coating } \\
\text { efficiency }\end{array}$ \\
\hline RGD-PLN (Low or 1\%) $(1.7 \mu \mathrm{mol} / \mathrm{L})$ & $0.8 \pm 0.4$ & $50 \% \pm 18 \%$ \\
RGD-PLN (Med or 10\%) $(16.6 \mu \mathrm{mol} / \mathrm{L})$ & $7.7 \pm 1.4$ & $46 \% \pm 8 \%$ \\
RGD-PLN (High or 30\%) $(49.7 \mu \mathrm{mol} / \mathrm{L})$ & $24.2 \pm 1.1$ & $48 \% \pm 6 \%$ \\
\hline
\end{tabular}

and $1871 \pm 82$ RGD per PLN for RGD-PLN (Low), RGD-PLN (Med), and RGD-PLN (High), respectively.

\section{Synergistic effect of DOX and MMC in MDA-MB-231 cells}

Compared to DOX alone $(0.46 \pm 0.04 \mu \mathrm{mol} / \mathrm{L})$ and MMC alone $(7.15 \pm 2.51 \mu \mathrm{mol} / \mathrm{L}), \mathrm{DOX}$ and MMC combination greatly enhanced the cytotoxicity in MDA-MB-231 cells evaluated by clonogenic assay (Figure $1 \mathrm{~A}$ ) with a $\mathrm{IC}_{50}$ of $0.12 \pm 0.05 \mu \mathrm{mol} / \mathrm{L}$. The combination index for DOX and MMC together is below 0.4 for fractions affected from 0.1-0.9 (Figure 1B, 1C), indicating strong synergy between DOX and MMC in MDA-MB-231
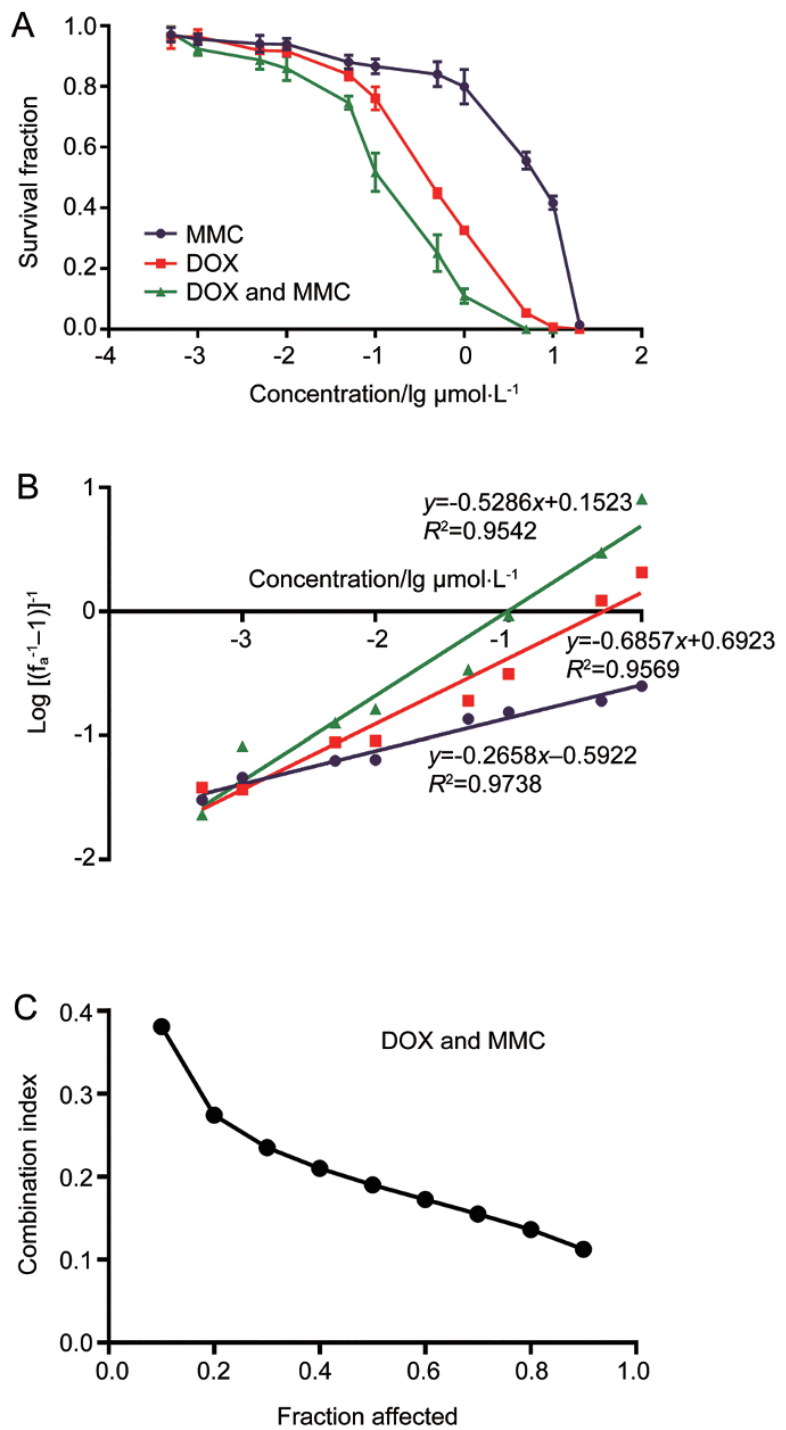

Figure 1. Evaluation of synergism between DOX and MMC in MDA-MB-231 cells. (A) Dose-response curve for the ability of cells to form colonies after treatment exposure of MMC and DOX, alone and in combination at DOX/ MMC molar ratio of 1:0.7 (Drug: 0.0005-20 $\mu \mathrm{mol} / \mathrm{L}$ ) for $1 \mathrm{~h}$. The [Drug] for DOX/MMC combination is represented by the concentration of DOX. Data are presented as mean \pm SEM. $n=6$. (B) Median effect plot for MMC and DOX, alone and in combination. $D_{m}$ and $m$ were calculated from $\mathrm{X}$-intercept and slope, respectively. (C) Combination index $(\mathrm{Cl})$ analysis of the interaction of MMC and DOX. 
cells at the molar ratio of 1.0: 0.7.

\section{RGD conjugation enhanced in vitro cytotoxicity of PLN}

Blank RGD-PLN (Low) and PLN exhibited no cytotoxicity at the studied concentrations and exposure times, whereas RGDPLN (High and Med) showed slight cytotoxicity only at high concentrations (Figure 2A). As portrayed in Figure 2B, the NP formulations of co-loaded DOX and MMC induced higher in vitro anticancer efficacy than free DOX and MMC, especially those with RGD conjugation. The $\mathrm{IC}_{50}$ of RGD-DMPLN (High) $(0.39 \pm 0.03 \mathrm{mg} / \mathrm{mL})$ and RGD-DMPLN (Med) $(0.44 \pm 0.04$ $\mathrm{mg} / \mathrm{mL})$ is $>2$-fold lower than 5 that of DMPLN $(1.0 \pm 0.29$ $\mathrm{mg} / \mathrm{mL})(P<0.05)$ and $>7$-fold lower than that of free DOX and MMC $\left(\mathrm{IC}_{50}\right.$ of $\left.3.2 \pm 1.2 \mathrm{mg} / \mathrm{mL}\right)(P<0.005)$. The dose-response curve of cell viability from the MTT assay for free DOX and MMC treatments confirmed the validity of the bioluminescence assay (Figure S2).

\section{RGD-DMPLN induced morphological change of cells in vitro}

To confirm the cellular binding of RGD-DMPLN and evaluate its effect on TNBC cell morphology, MDA-MB-231-luc-
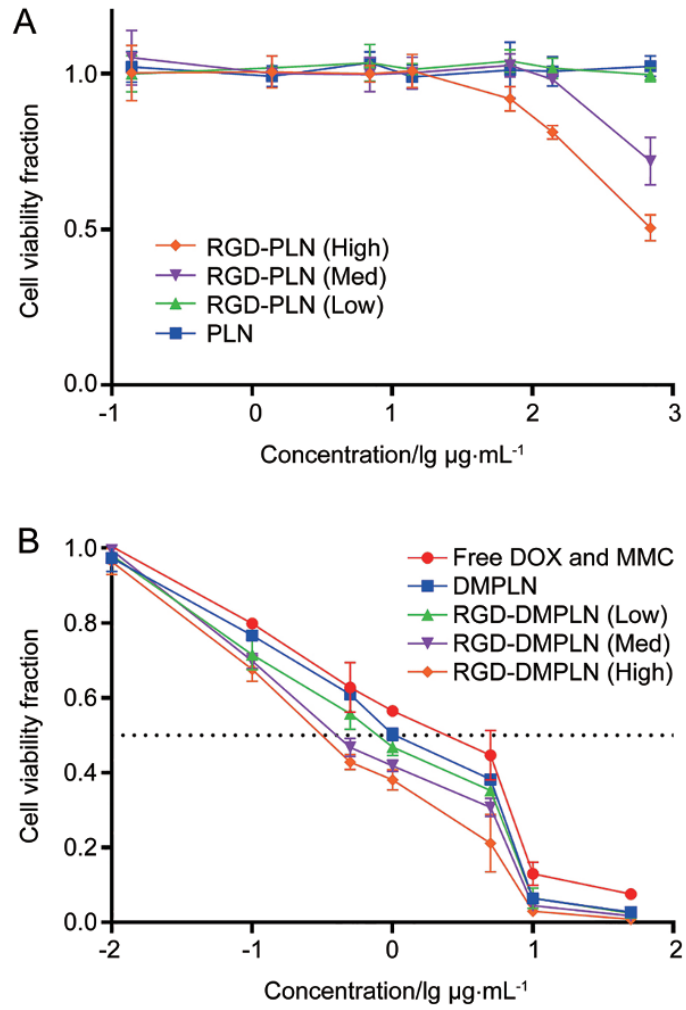

Figure 2. In vitro cytotoxicity of particles in MDA-MB-231-luc-D3H2LN cells. Cells were exposed to seven concentrations of (A) blank NPs (PLN: 0.139-695 $\mu \mathrm{g} / \mathrm{mL}$ ) or (B) free and nanoparticle DOX and MMC formulations (DOX: 0.01-50 $\mathrm{gg} / \mathrm{mL}$ ) for $1 \mathrm{~h}$. In both (A) and (B) cells were washed and allowed to proliferate for $24 \mathrm{~h}$ before evaluated by ATP bioluminescence assay. At [DOX] of $50 \mu \mathrm{g} / \mathrm{mL}$ in NP formulation, the corresponding PLN is $695 \mu \mathrm{g} / \mathrm{mL}$. All formulations of DOX and MMC were given at the DOX/MMC ratio of 1:0.7. Data are presented as mean \pm SD. $n=3$ for each formulation.
D3H2LN cells seeded in vitro on vitronectin-coated 96-well plates were observed using microscope for $1 \mathrm{~h}$ following NP treatment. The cells gradually changed from a spread or elongated shape to a less spread or rounded shape in the RGDDMPLN- (High and Med) treated groups illustrated by bright field optical images (Figure S3A). Shape factor (f), a widely used parameter to characterize the cell morphology state ${ }^{[5,56]}$, was used to quantify the morphological changes at $0,10,30$ and $60 \mathrm{~min}$ after particle addition. For perfectly rounded cells, $f=1$, whereas for elongated or star-shaped cells, $f<1$ and approached 0 , depending on the degree of spread. The $f$ values before treatment, for all groups, were approximately 0.45 but increased to approximately 0.76 for RGD-DMPLN(High and Med) treated cells at $1 \mathrm{~h}$ (Figure S3B), which significantly increased over $1 \mathrm{~h}$ compared to other treatment groups $(P<0.0005)$. The morphological change is likely due to the disruption of the binding of cell integrin receptors to the extracellular matrix (ECM, represented by the vitronectin-coated plate) by RGD, an integrin antagonist, on RGD-DMPLN. Compared to the saline treatment, RGD-DMPLN (Low), RGD peptide, DMPLN and free DOX/MMC treatment did not induce significant shape changes. The change in morphology may be correlated with the enhanced in vitro cytotoxicity of RGD-DMPLN (High and Med). Compared to RGD-DMPLN, the free RGD peptide could not induce changes in cell morphology, which is likely caused by the difference between the two formulations in binding affinity. RGD-DMPLN is expected to have higher binding affinity to integrin-expressing cells due to the multivalent effect of ligand presenting nanoparticles. It was reported that the multivalency effect occurs when multiple ligands on nanoparticles bind to multiple receptors simultaneously, which usually increases the binding affinity by 10-1000fold compared to free ligands ${ }^{[57]}$.

Biodistribution of nanoparticles in lung metastasis-bearing mice Whole body biodistribution of ICG-loaded NPs was monitored non-invasively using a Xenogen imager at predetermined times up to $24 \mathrm{~h}$ following intravenous injection of PLN or RGD-PLN (Figure 3A). The fluorescence images of lung regions are presented in Figure 3B. The fluorescence intensity of the whole body decreased with time, and the high intensity region shifted gradually from the liver area to abdominal area. Zoomed-in chest fluorescence images revealed rapid $\mathrm{NP}$ accumulation in the lung regions within 15 min post injection (Figure 3B). The fluorescence intensity from the lung region decreased with time but was still detectable at $24 \mathrm{~h}$ post injection for RGD-PLN (High) and RGD-PLN (Med) but not for RGD-PLN (Low) and PLN. The fluorescence radiant efficiency from the lung region was quantified and plotted as a fold increase relative to the efficiency prior to injection $v$ s time in Figure 3C. It was seen that the lung accumulation of ICGlabelled RGD-PLN (Med) was the highest compared to RGDPLN (High), RGD-PLN (Low) and PLN.

In separate experiments, mice were sacrificed $4 \mathrm{~h}$ following NPs injection, and major organs, including the liver, spleen, kidneys, heart and lungs, were resected to evaluate ex vivo 
A

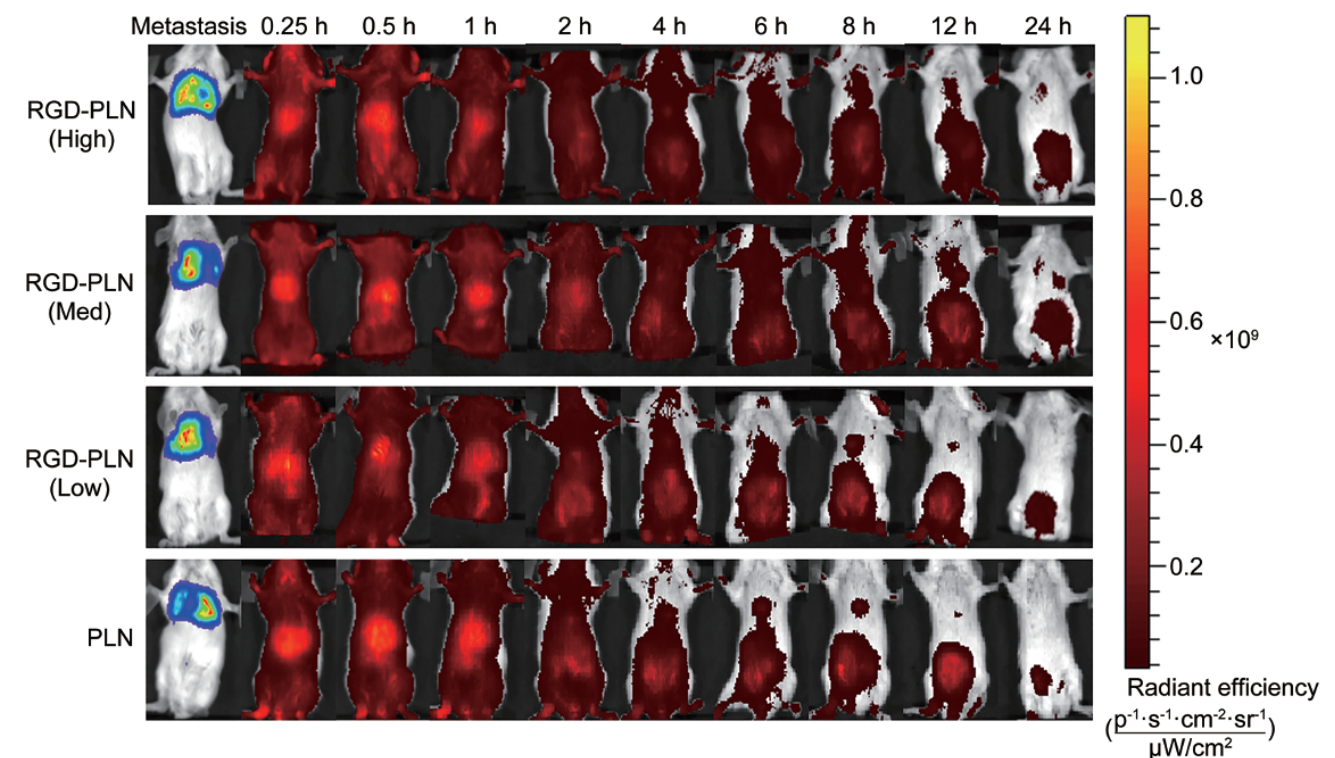

B

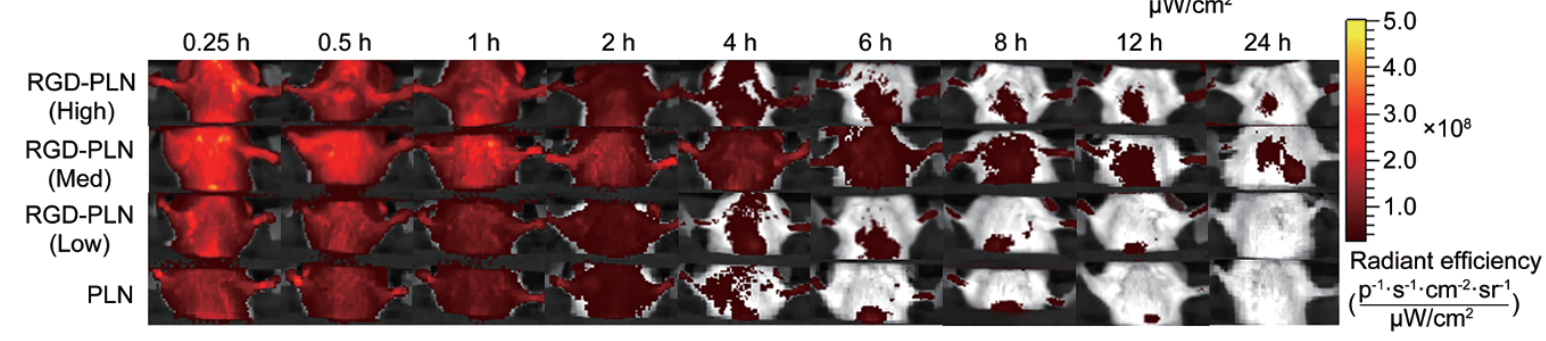

C

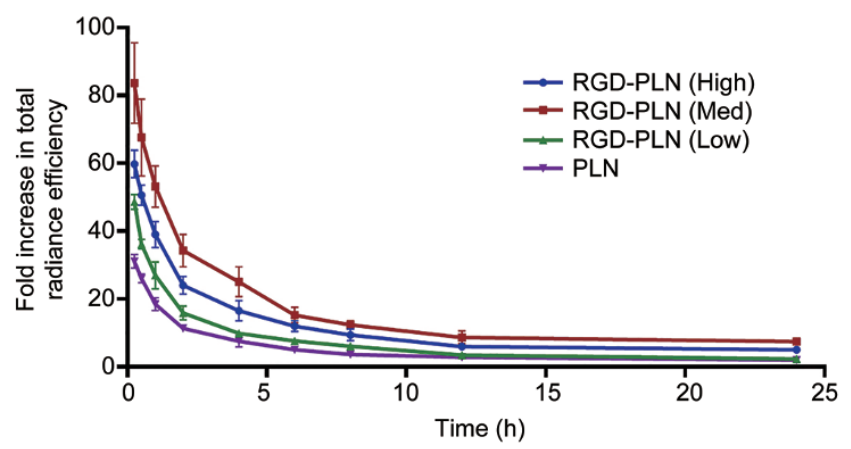

D
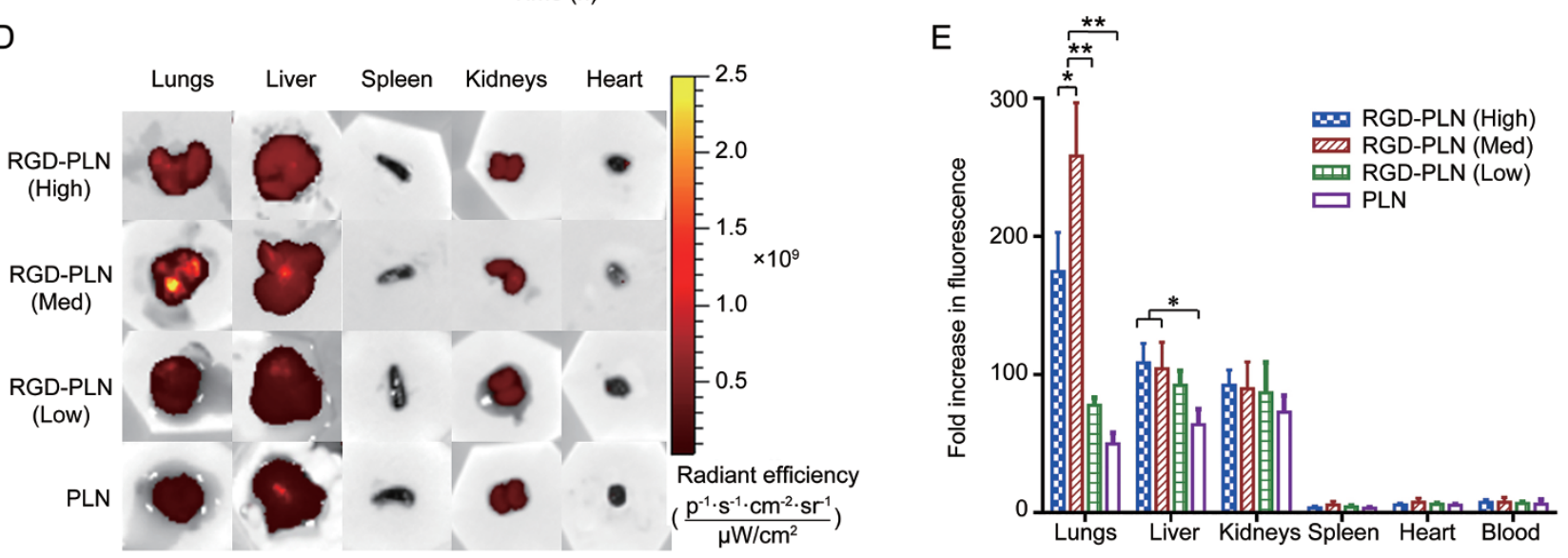

Figure 3. Fluorescent imaging of ICG labelled nanoparticle biodistributions in the MDA-MB 231-luc-D3H2LN lung metastasis SCID model of TNBC. (A) Whole body biodistribution images up to $24 \mathrm{~h}$ using Xenogen IVIS Spectrum System 100 with Ex: $745 \mathrm{~nm}$ and Em: $820 \mathrm{~nm}$. (B) Zoomed in images of the accumulation of NPs in the lungs up to $24 \mathrm{~h}$. (C) Quantitative presentation of nanoparticle biodistribution in lung region up to $24 \mathrm{~h}$. (D) Qualitative presentation of organ biodistribution ex vivo at $4 \mathrm{~h}$. (E) Quantitative presentation of ex vivo organ biodistribution at $4 \mathrm{~h}$. The data are represented as mean \pm SD. $n=3$. ${ }^{*} P<0.05,{ }^{* *} P<0.01$. 
tissue distribution of NPs. As shown in Figure 3D, strong fluorescence signals were observed in the lungs and drugeliminating organs (liver and kidneys), while the spleen, heart and blood showed negligible fluorescence signals. Compared to the other groups, stronger fluorescence intensity was observed in the RGD-PLN (Med) group. The fluorescence radiant efficiency of each organ was measured and expressed as fold increase based on radiant efficiency of the respective organ before injection (Figure 3E). RGD-PLN (Med) showed significantly higher accumulation in the lungs compared to RGD-PLN (High) $(P<0.05)$, RGD-PLN (Low) $(P<0.0005)$ and PLN $(P<0.0005)$. RGD-PLN (Med) was used in the following studies, including the toxicity and in vivo efficacy evaluations.

\section{Microscopic distribution of NPs in the metastatic lung tumor}

To observe the microscopic distribution of NPs within the metastatic lung tumor at $4 \mathrm{~h}$ post iv injection of FITC-covalently labelled RGD-PLN (Med), PLN, or saline, the lungs were sectioned and stained with H\&E, Alexa Fluor ${ }^{\circledR}$ 647-labelled CD-31 antibody for blood vessels, and DAPI for cell nuclei. The representative confocal fluorescence images of metastatic lung tumors showed significantly higher accumulation of RGD-PLN (Med) than PLN; RGD-PLN (Med) accumulated in the tumor vasculature and tumor tissue, whereas PLN accumulated mainly in the tumor tissue (Figure 4).

Nanoparticle formulation of DOX and MMC reduced general, cardiac and hepatic toxicity

Dose tolerance and toxicity of various formulations were evaluated using free DOX/MMC solutions, DMPLN, or RGDDMPLN (Med) at various equivalent doses of $\operatorname{DOX}(3,6,10$ and $15 \mathrm{mg} / \mathrm{kg}$ ) and $\mathrm{MMC}$ at a molar ratio of 1.0:0.7. Body weight was monitored for 1 week and other toxicity assess- ments were performed at $\mathrm{d} 7$ after treatment. All of the mice treated with free DOX and MMC solutions (6-15 mg/kg) exhibited clinical signs of severe toxicity, such as significant weight loss of over $20 \%$ from the initial weight, hunched back and ruffled fur coats, thereby reaching an experimental end point (Table S2). Therefore, a $3 \mathrm{mg} / \mathrm{kg}$ DOX dose in free solution was considered tolerable in our SCID mouse lung metastasis model, which is consistent with previous findings ${ }^{[58]}$, and was selected for evaluation of therapeutic efficacy of free DOX and MMC. Treatment with DMPLN or RGD-DMPLN at all doses (3-15 mg/kg DOX dose) showed no significant general toxicity (Table S2).

The acute cardiotoxicity of the nanoparticles was evaluated for the treatment-tolerated groups at $7 \mathrm{~d}$ post treatment. Cardiotoxicity was assessed by the presence or absence of myocardial vacuolation in H\&E stained heart sections, which is indicative of treatment-related myocardial degeneration ${ }^{[59]}$. The presence of myocardial vacuolation was observed in heart sections from free drugs ( 3 and $10 \mathrm{mg} / \mathrm{kg}$ ), DMPLN (15 $\mathrm{mg} / \mathrm{kg})$, and RGD-DMPLN (15 mg/kg) treated groups but not in saline, DMPLN (10 mg/kg) and RGD-DMPLN $(10 \mathrm{mg} / \mathrm{kg})$ treated groups (Figure 5A). The presence of acute cardiotoxicity was also determined by the level of cardiac troponin I (cTnI) in mouse serum ${ }^{[60]}$. The level of cTnI was significantly elevated in serum from free drug ( $3 \mathrm{mg} / \mathrm{kg})$, DMPLN (15 $\mathrm{mg} / \mathrm{kg}$ ) and RGD-DMPLN (15 mg/kg) treated mice (Figure 5B). Compared to the saline-treated group, no significant elevation of cTnl was observed in the DMPLN $(10 \mathrm{mg} / \mathrm{kg})$ and RGD-DMPLN (10 mg/kg) treated groups (Figure 5B).

To further confirm the safety of the chosen doses for an in vivo efficacy study, histopathology changes of liver tissue and ALT levels were evaluated one-week post treatment with (1) Saline, (2) Free DOX and MMC (3 mg/kg), (3) DMPLN (10

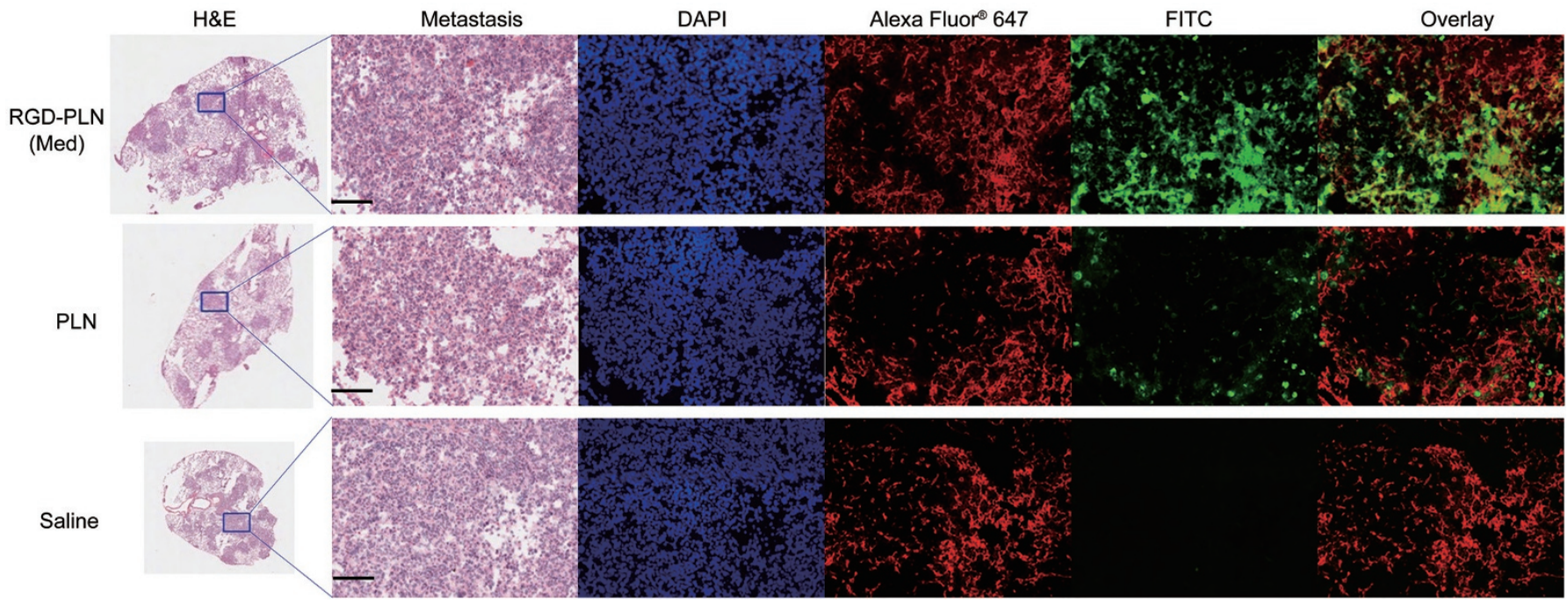

Figure 4. Nanoparticle distribution in the metastasis-bearing lungs inoculated with MDA-MB-231-luc-D3H2LN cells. Lungs were resected $4 \mathrm{~h}$ following treatment of FITC-labelled RGD-PLN (Med), PLN and saline. Transverse sections of the lung were made and metastatic tumor nodules were shown purple under H\&E staining. The same tumor area that is indicated by blue region in each H\&E sections which was zoomed and inspected by the following staining. DAPI-stained cell nuclei are shown in blue. Alexa Fluor ${ }^{\circledR} 647$ labelled CD-31 antibody stained blood vessel. Scale bar=200 $\mu \mathrm{m}$ for all zoomed images. 

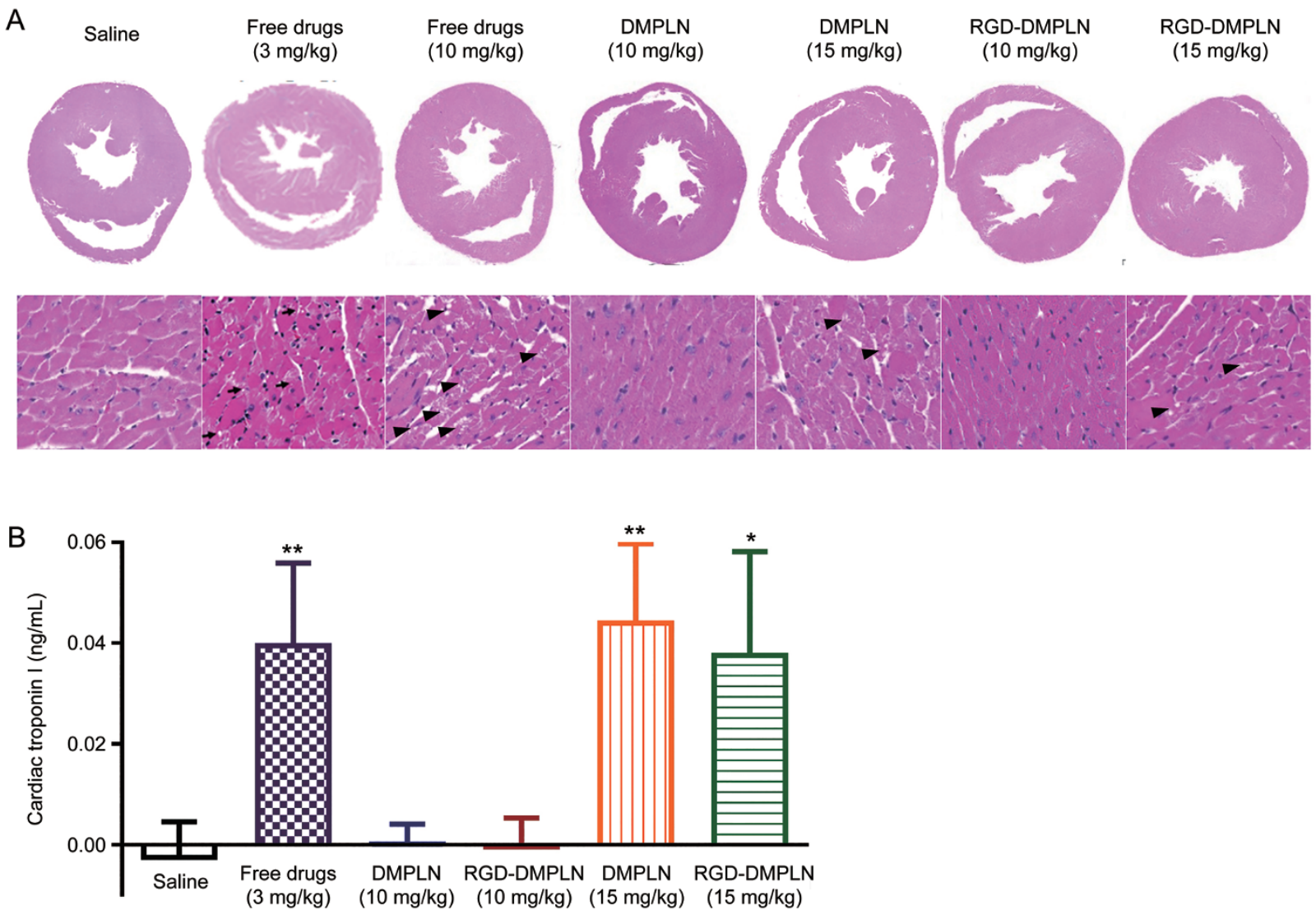

C
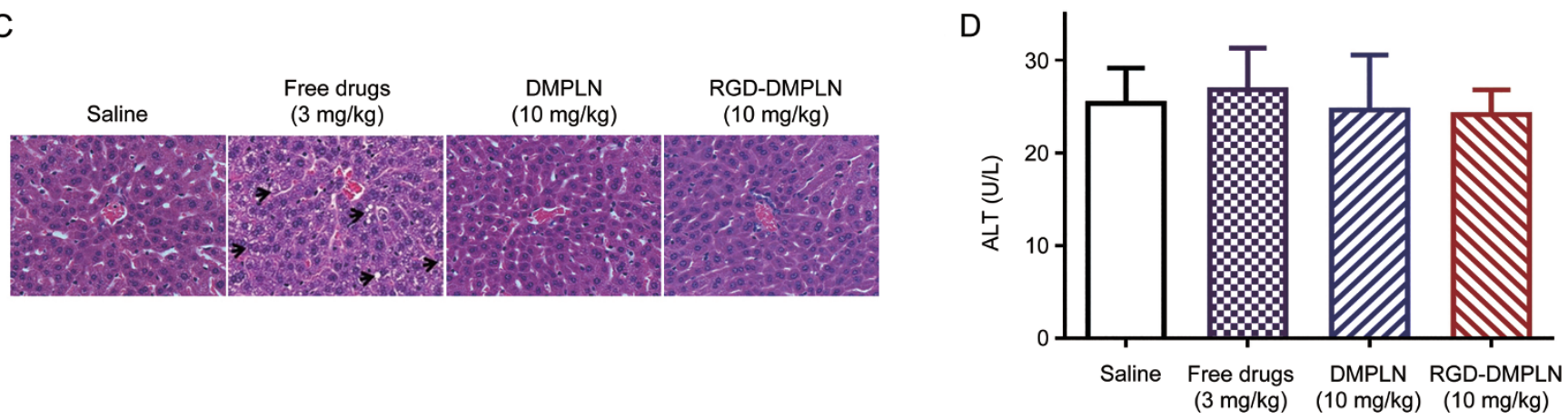

Figure 5. Evaluation of cardiac and hepatic toxicity for tolerated dose evaluation. All the mice were inoculated iv with MDA-MB-231-luc-D3H2LN cells a week before treatment initiation. Hearts and blood were taken on day 7 post treatment. Hearts from mice receiving saline, free drugs, DMPLN and RGD-DMPLN were formalin fixed, paraffin embedded and stained with H\&E. (A) Representative images of transverse section of whole heart and zoomed-in areas. Myocardial vacuolation (black arrows) was shown in free drugs (3 and $10 \mathrm{mg} / \mathrm{kg}$ ), DMPLN (15 mg/kg) and RGD-DMPLN (15 mg/kg) treated groups. (B) Assessment of cardiac troponin I levels in serum samples. (C) H\&E stained liver sections. Hepatotoxicity (hepatocellular vacuolation indicated by black arrows) was seen in free drugs group. (D) ALT level assayed from mice serum. All H\&E stained images were scanned at $20 \times$ magnification. All data are presented as mean \pm SD. ${ }^{*} P<0.05,{ }^{* *} P<0.01$.

$\mathrm{mg} / \mathrm{kg}$ ) and (4) RGD-DMPLN (10 mg/ kg). Compared to saline control, livers of mice treated with DMPLN $(10 \mathrm{mg} / \mathrm{kg})$ and RGD-DMPLN $(10 \mathrm{mg} / \mathrm{kg})$ appeared normal and showed no signs of toxicity (Figure 5C), in spite of the higher hepatic uptake of RGD-PLN observed (Figure 3D, 3E). However, compared to the other groups, the free drug $(3 \mathrm{mg} / \mathrm{kg})$ treated group exhibited some pathological changes with occasional micro-vesicular hepatocellular vacuolation (Figure 5C). Com- pared to saline, the ALT assay showed no elevation in any treated group (Figure 5D).

These results suggest that encapsulating the drug combination within the PLN greatly mitigated the toxicity induced by free DOX and MMC (Figure 5, Figure S4 and Table S2) and are consistent with our previous observations ${ }^{[38]}$. As DMPLN $(10 \mathrm{mg} / \mathrm{kg})$ and RGD-DMPLN $(10 \mathrm{mg} / \mathrm{kg})$ did not lead to any significant acute cardiac or hepatic toxicity, these formulations 
were used in the following in vivo efficacy study.

\section{RGD-DMPLN inhibited the growth of lung metastases and prolonged survival compared to DMPLN and free drugs}

Tumor progression was monitored by bioluminescence imaging to visualize and quantify tumor burden without the need for animal sacrifice at each time point of analysis. In general, the relative level of bioluminescence signal correlates with metastatic burden ${ }^{[6]]}$. Bioluminescent images were acquired every week for four weeks, and the survival of the treated mice was monitored based on humane end points. Body weight was recorded every week during treatment and reported in Figure S5. Compared to $\mathrm{d} 0$. the fold increase in tumor bioluminescence radiance (FI-TBR) was quantified as a measure of tumor burden in the lungs and is presented in Figure 6A. Representative bioluminescence images at the 28th day following tumor inoculation for each treatment group are shown in Figure 6B. Compared to saline, RGD-DMPLN ( $3 \mathrm{mg} / \mathrm{kg})$ showed significant tumor inhibition with a 2.3-fold decrease in FI-TBR $(P<0.05)$, whereas treatment with free drugs $(3 \mathrm{mg} / \mathrm{kg})$ did not show a significant difference from the saline control. However, compared to saline and free drugs, the median survival time of the RGD-DMPLN (3 mg/ $\mathrm{kg}$ ) treatment group was not significant (Figure 6F, 6G).

To try to achieve a better survival rate, a dose escalation test was performed using NP formulations at a $10 \mathrm{mg} / \mathrm{kg}$ dose that did not show acute toxicity (Figure 5, S4 and Table S2). Since severe signs of toxicity were observed with free DOX and MMC at 6 or $10 \mathrm{mg} / \mathrm{kg}$ doses in the dose tolerability study, the NP formulations could only be compared to free drugs at a tolerable dose of $3 \mathrm{mg} / \mathrm{kg}$. At the 28th day following tumor inoculation, compared to free drug treatment, DMPLN $(10 \mathrm{mg} / \mathrm{kg})$ and RGD-DMPLN $(10 \mathrm{mg} / \mathrm{kg})$ reduced the FI-TBR by 6.6 -fold and 31-fold, respectively $(P<0.0005)$. Furthermore, RGD-DMPLN (10 mg/kg) produced more significant improvement in suppression of metastasis growth than DMPLN $(10 \mathrm{mg} / \mathrm{kg})$ with a 4.7 -fold decrease in FI-TBR $(P<0.0005)$ (Figure 6A, 6B). At $\mathrm{d} 28$, the weight of the lungs, a measure of tumor burden, from RGD-DMPLN and DMPLN $(10 \mathrm{mg} / \mathrm{kg})$ treated mice, respectively, was 3.5 -fold $(P<0.0005)$ and 2.1-fold $(P<0.0005)$ less than the lungs from the free drug treatment group, and the RGD-DMPLN $(10 \mathrm{mg} / \mathrm{kg})$ treatment group was 1.6-fold $(P<0.05)$ less than the DMPLN $(10$ $\mathrm{mg} / \mathrm{kg}$ ) treatment group (Figure $6 \mathrm{C}$ ). The lung metastasis area index in the DMPLN $(10 \mathrm{mg} / \mathrm{kg})$ treated group was 1.7fold $(P<0.0005)$ lower and in RGD-DMPLN $(10 \mathrm{mg} / \mathrm{kg})$ treated group was 4.0 -fold $(P<0.0005)$ lower than the free drug group; in other words, compared to non-targeted DMPLN, RGD conjugation further lowered the metastasis area index by 2.4fold $(P<0.0005)$ (Figure 6D, 6E). The metastasis burden results were correlated with host survival, and the mean survival time increased by $24 \%$ with DMPLN $(10 \mathrm{mg} / \mathrm{kg})$ treatment $(26 \pm 4 \mathrm{~d}, P<0.05)$ and $62 \%$ with RGD-DMPLN $(10 \mathrm{mg} / \mathrm{kg})$ treatment $(34 \pm 6 \mathrm{~d}, P<0.005)$ compared to free drug group $(21 \pm 1 \mathrm{~d})$ (Figure 6F, 6G). Note that up to $21 \mathrm{~d}$, the mice treated with DMPLN $(10 \mathrm{mg} / \mathrm{kg})$ or RGD-DMPLN $(10 \mathrm{mg} / \mathrm{kg})$ did not lose body weight, whereas the other treatment groups (saline, free drug $3 \mathrm{mg} / \mathrm{kg}$, RGD-PLN $3 \mathrm{mg} / \mathrm{kg}$ ) lost $>20 \%$ of body weight (Figure S5).

\section{Discussion}

This study investigated the effect of surface RGD density on nanoparticle biodistribution in a lung metastasis model for the first time. Among various NP formulations studied, RGDPLN (Med) was found to have the highest accumulation in the metastasis-bearing lungs. Previously, compared to RGDSLN with medium and high RGD concentrations, RGD-SLN (Low) was reported to have the highest accumulation in primary tumors, likely owing to avoidance of extensive hepatic uptake $^{[33]}$. The difference in optimal ligand density between the primary breast tumor model and the current lung metastasis model is attributable to the difference in tumor location. In the lung metastasis model, the intravenously injected dose will pass the metastasis-bearing lungs before entering the liver, and hence RGD-PLN will have a chance to bind to the angiogenic tumor vasculature and tumor cells before reaching and being taken up by the liver. In contrast, in the primary breast tumor model, the majority of the dose will pass through the liver before reaching the tumor site. Moreover, compared to primary tumors, the lungs are highly vascularized, presenting more angiogenic blood vessels adjacent to tumor cells. As a result, increasing the RGD density enhanced the accumulation of RGD-PLN in the metastasis regions of the lungs. This observation suggests that optimal ligand density may vary with tumor sites due to their unique physiology and anatomy. Microscopic images (Figure 4) revealed that RGD-PLN (Med) was much more abundant in the lung metastasis compared to non-targeted PLN. RGD-PLN achieved dual targeting by binding with the av $\beta 3$ overexpressing tumor vasculature and metastatic tumor cells, whereas PLN were removed quickly by the circulation with a small portion mainly distributing outside of tumor vasculature. Although RGD-PLN (Med) may be bound with the tumor vasculature due to the binding site barrier effect ${ }^{[62]}$, noticeable NP distribution outside the vessels was also seen (Figure 4). Targeting drugs to both tumor vasculature and tumor cells by RGD-PLN could be therapeutically beneficial due to the anti-angiogenic and anticancer effects of the DOX-MMC combination observed in our previous work ${ }^{[41]}$.

The present study has demonstrated the efficacy of av $\beta 3$ integrin-targeted RGD-DMPLN in an experimental lung metastasis mouse model of TNBC. To the best of our knowledge, this is the first time an RGD-conjugated nanoparticle delivery system was used for treatment of lung metastases of TNBC. The experimental metastasis model produced consistent tumor burden in the lungs one week after inoculation with small deviations (Figure 6), which provided a rapid and reproducible platform to evaluate in vivo efficacy of various formulations. RGD-DMPLN $(10 \mathrm{mg} / \mathrm{kg})$ resulted in a longer survival time and significant inhibition of lung metastasis progression as reflected in significantly lower lung weights, lower metastasis area indices as well as lower tumor biolumines- 
A

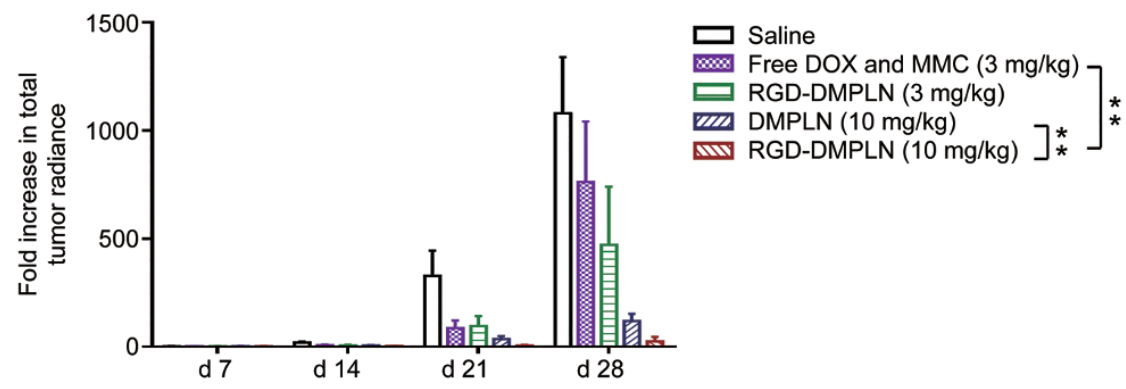

B

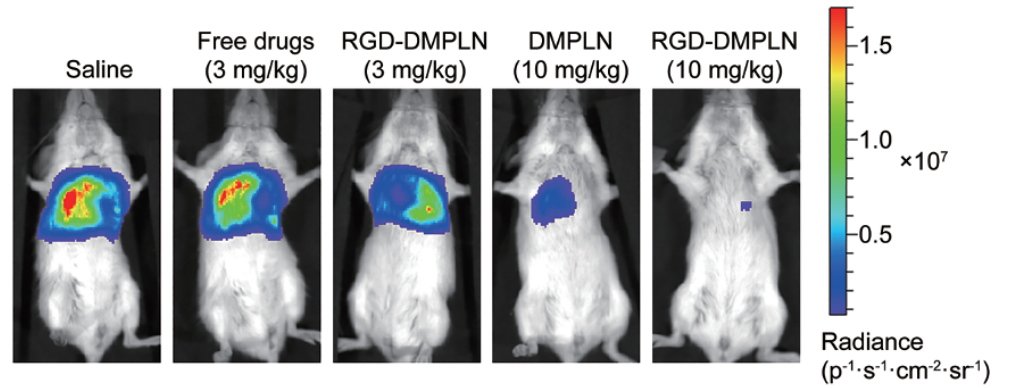

C
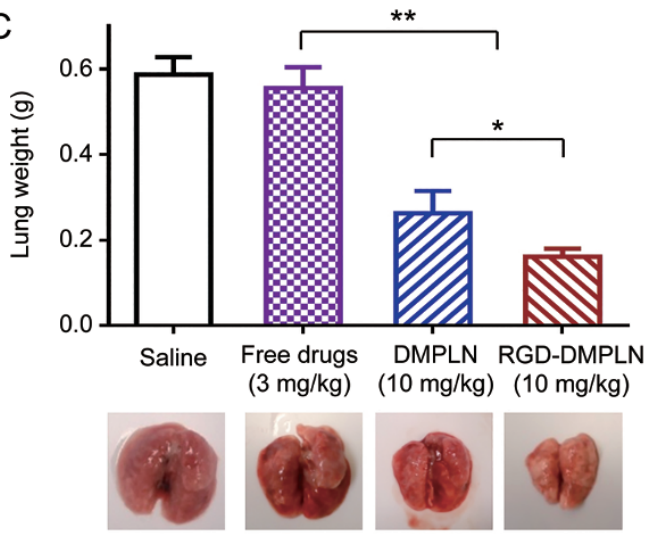

E

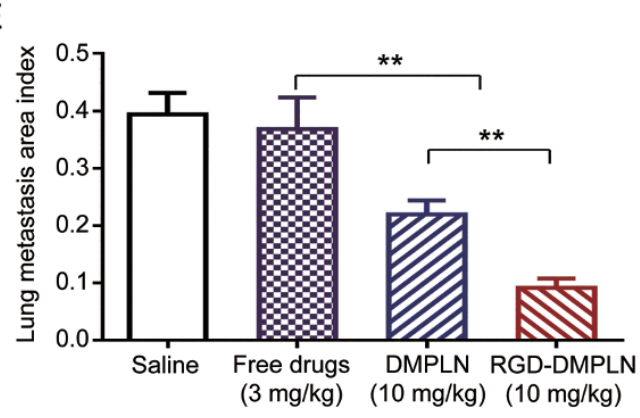

G

\begin{tabular}{|c|c|c|c|c|}
\hline & & Groups & $\begin{array}{l}\text { Mean survival } \\
\text { time (d) }\end{array}$ & $\begin{array}{l}\text { Median survival } \\
\text { time (d) }\end{array}$ \\
\hline & & Saline $(n=4)$ & $20 \pm 2$ & 21 \\
\hline & & $\begin{array}{l}\text { Free drugs } \\
(3 \mathrm{mg} / \mathrm{kg}, n=5)\end{array}$ & $21 \pm 1$ & 21 \\
\hline & & $\begin{array}{l}\text { RGD-DMPLN } \\
(3 \mathrm{mg} / \mathrm{kg}, n=5)\end{array}$ & $22 \pm 2$ & 21 \\
\hline & & $\begin{array}{l}\text { DMPLN } \\
(10 \mathrm{mg} / \mathrm{kg}, n=6)\end{array}$ & $26 \pm 4$ & 24.5 \\
\hline & & $\begin{array}{l}\text { RGD-DMPLN } \\
(10 \mathrm{mg} / \mathrm{kg}, n=6)\end{array}$ & $34 \pm 6$ & 33 \\
\hline
\end{tabular}

F

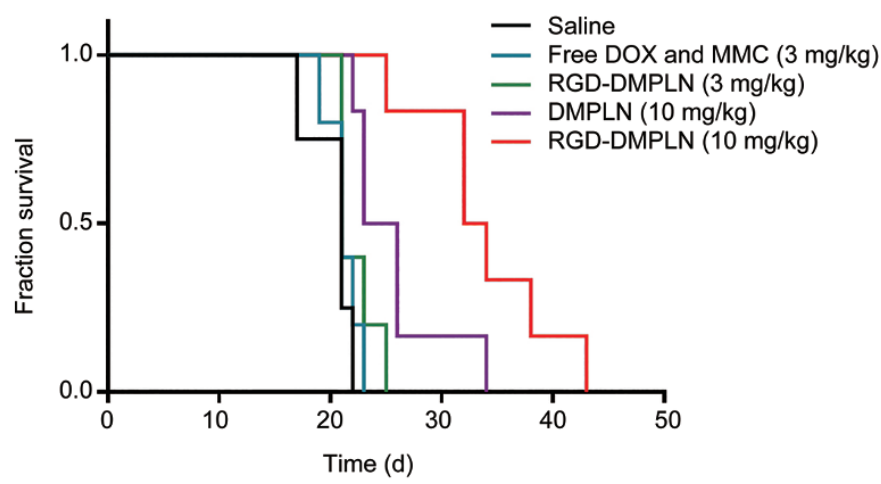

$(10 \mathrm{mg} / \mathrm{kg}) \quad(10 \mathrm{mg} / \mathrm{kg})$
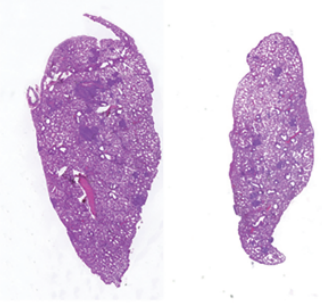

Figure 6. Inhibition of MDA-MB-231-luc-D3H2LN lung metastasis growth and extension of animal survival. (A) Quantification of tumor burden measured using bioluminescent imaging once a week. Treatments of saline ( $n=4)$, free DOX and MMC (3 mg/kg DOX, $n=5)$, RGD-DMPLN (3 mg/kg DOX, $n=5)$, DMPLN (10 mg/kg DOX, $n=6)$, RGD-DMPLN (10 mg/kg DOX, $n=6)$ were given intravenously via the tail vein one week after tumor inoculation. (B) Representative in vivo bioluminescent images of mice from each treatment group on d 28 after tumor inoculation. (C) Average weight and representative images of excised lungs on $d 28$. Data represents mean \pm SD. $n=4$. (D) Representative histological images of H\&E stained left lungs at $d 28$. The dark purple regions represent metastatic nodules. (E) Quantification of metastases by lung metastasis area index ( $n=9$ for each group). (F) Kaplan-Meier plot of the tumor-bearing mice for all groups. (G) Mean and median survival time of the tumor-bearing mice. All data were presented as mean \pm SD. ${ }^{* *} P<0.01$. 
cence signals compared to free drugs $(3 \mathrm{mg} / \mathrm{kg})$ and DMPLN $(10 \mathrm{mg} / \mathrm{kg})$ treatment. This enhanced efficacy is attributable to several factors. First, significantly higher accumulation of RGD-PLN than the non-targeted PLN was observed in the metastasis-bearing lungs (Figure 3). The dual targetability of RGD-DMPLN allows spatiotemporal co-delivery and sustained release of cytotoxic DOX and MMC at a synergistic ratio to tumor vasculature and tumor cells ${ }^{[38]}$, resulting in direct cytotoxic effects on the cancer cells and tumor vascular endothelium. Second, the synergism between DOX and MMC demonstrated in TNBC MDA-MB-231 cells (Figure 1) and other cell lines ${ }^{[35-37,39]}$ enhances cytotoxicity and genotoxicity. The mechanism of DOX-MMC synergy has been proposed by Shuhendler et $a l^{[35,36]}$. The intracellular formaldehyde generated by MMC metabolism enhanced the cytotoxicity of DOX; and DNA alkylation by MMC initiated DNA repair activities, which increases the chance of collision of DNA repair proteins and impaired topoisomerase II, resulting in significant DNA double-strand breaks (DSBs). Since the majority of TNBC express mutated DNA damage-repair genes (eg, MDAMB-231 cells mutated in TP53 gene $\left.{ }^{[47]}\right)$, the DOX-MMC combination-induced DSBs could be more detrimental to TNBC cells. Third, the vascular disruption and inhibition of tumor angiogenesis ${ }^{[63,64]}$ could also inhibit tumor growth ${ }^{[65]}$. In the case of metastasis with microsized lesions, where enhanced permeability and retention effect may not be operative for NP extravasation to tumor cells, targeting tumor angiogenesis and vasculature would be an effective therapeutic strategy ${ }^{[65]}$.

In this work, only a single-dose treatment was administered. Clinically, multiple treatment doses over a period of time are applied to patients. Given that no general, cardiac or hepatic toxicity was observed from the first dose of NP treatment (Figure 5 and S4), a second dose of RGD-DMPLN might be administered to improve the survival rate and even provide curative treatment.

In conclusion, this work has demonstrated, for the first time, that dual-targeted RGD-DMPLN with optimal RGD density and a synergistic drug combination significantly inhibited the progression of lung metastases of TNBC and prolonged the host survival compared to non-targeted DMPLN and free drug combinations without inducing noticeable toxicity. This pre-clinical evaluation suggests that the RGD-DMPLN formulation could potentially provide more effective treatment than standard chemotherapeutic regimens for lung metastases of TNBC.

\section{Acknowledgements}

The authors gratefully thank the Canadian Breast Cancer Foundation-Ontario Region for supporting this work as well as the Canadian Institutes of Health Research (CIHR) and the National Science and Engineering Research Council (NSERC) of Canada for the Equipment Grants. NSERC CGM and Graduate Department of Pharmaceutical Sciences TopUp scholarships awarded to Tian ZHANG and Dan SHAN, a CIHR Travel Award awarded to Tian ZHANG, an Ontario Graduate Scholarship and Pfizer scholarship awarded to
Preethy PRASAD, the University of Toronto Fellowship and Nanotechnology Network Award and the Anna and Alex Beverly Fellowship awarded to Dan SHAN and are also gratefully acknowledged.

\section{Author contribution}

Tian ZHANG, Preethy PRASAD, Ping CAI, Chunsheng HE, and Xiao Yu WU designed the studies; Tian ZHANG, Preethy PRASAD, Ping CAI, and Chunsheng HE performed the experiments. Tian ZHANG, Preethy PRASAD, and Xiao Yu WU wrote the manuscript with the assistance of Ping CAI, Chunsheng HE, and Dan SHAN. Andrew M RAUTH and Xiao Yu WU supervised the studies and edited the manuscript. All authors have read and approved the final manuscript.

\section{Supplementary information}

Supplementary information is available at Acta Pharmacologica Sinica's website

\section{References}

1 Pal SK, Childs BH, Pegram M. Triple negative breast cancer: unmet medical needs. Breast Cancer Res Treat 2011; 125: 627-36.

2 Stockmans G, Deraedt K, Wildiers H, Moerman P, Paridaens R. Triplenegative breast cancer. Curr Opin Oncol 2008; 20: 614-20.

3 Irvin WJ Jr, Carey LA. What is triple-negative breast cancer? Eur J Cancer 2008; 44: 2799-805.

4 Telli ML, Carlson RW. First-line chemotherapy for metastatic breast cancer. Clin Breast Cancer 2009; 9: S66-72.

5 Griffiths CL, Olin JL. Triple negative breast cancer: a brief review of its characteristics and treatment options. J Pharm Pract 2012; 25: 319-23.

6 Stover DG, Bell CF, Tolaney SM. Neoadjuvant and adjuvant chemotherapy considerations for triple-negative breast cancer. AJHO 2016; 12: 6-12.

7 Collignon J, Lousberg L, Schroeder H, Jerusalem G. Triple-negative breast cancer: treatment challenges and solutions. Breast Cancer 2016; 8: 93-107.

8 Yao H, He G, Yan S, Chen C, Song L, Rosol TJ, et al. Triple-negative breast cancer: is there a treatment on the horizon? Oncotarget 2017; 8: 1913-24.

9 Kassam F, Enright K, Dent R, Dranitsaris G, Myers J, Flynn C, et al. Survival outcomes for patients with metastatic triple-negative breast cancer: implications for clinical practice and trial design. Clin Breast Cancer 2009; 9: 29-33.

10 Cardillo TM, Govindan SV, Sharkey RM, Trisal P, Arrojo R, Liu D, et al. Sacituzumab Govitecan (IMMU-132), an anti-Trop-2/SN-38 antibodydrug conjugate: characterization and efficacy in pancreatic, gastric, and other cancers. Bioconjug Chem 2015; 26: 919-31.

11 O'Shaughnessy J, Osborne C, Pippen JE, Yoffe M, Patt D, Rocha C, et al. Iniparib plus chemotherapy in metastatic triple-negative breast cancer. N Engl J Med 2011; 364: 205-14.

12 Saha P, Nanda R. Concepts and targets in triple-negative breast cancer: recent results and clinical implications. Ther Adv Med Oncol 2016; 8: 351-9.

13 Lehmann BD, Jovanovic B, Chen X, Estrada MV, Johnson KN, Shyr Y, et al. Refinement of triple-negative breast cancer molecular subtypes: implications for neoadjuvant chemotherapy selection. PLoS One 2016; 11: e0157368.

14 Lehmann BD, Bauer JA, Chen X, Sanders ME, Chakravarthy AB, Shyr Y, 
et al. Identification of human triple-negative breast cancer subtypes and preclinical models for selection of targeted therapies. J Clin Invest 2011; 121: 2750-67.

15 White DE, Muller WJ. Multifaceted roles of integrins in breast cancer metastasis. J Mammary Gland Biol Neoplasia 2007; 12: 135-42.

16 Desgrosellier JS, Barnes LA, Shields DJ, Huang M, Lau SK, Prevost $\mathrm{N}$, et al. An integrin alpha(v)beta(3)-c-Src oncogenic unit promotes anchorage-independence and tumor progression. Nat Med 2009; 15 : 1163-9.

17 Desgrosellier JS, Cheresh DA. Integrins in cancer: biological implications and therapeutic opportunities. Nat Rev Cancer 2010; 10: 9-22.

18 Weis SM, Cheresh DA. alphaV integrins in angiogenesis and cancer. Cold Spring Harb Perspect Med 2011; 1: a006478.

19 Cox D, Brennan M, Moran N. Integrins as therapeutic targets: lessons and opportunities. Nat Rev Drug Discov 2010; 9: 804-20.

20 Seguin L, Desgrosellier JS, Weis SM, Cheresh DA. Integrins and cancer: regulators of cancer stemness, metastasis, and drug resistance. Trends Cell Biol 2015; 25: 234-40.

21 Takayama S, Ishii S, Ikeda T, Masamura S, Doi M, Kitajima M. The relationship between bone metastasis from human breast cancer and integrin alpha(v)beta(3) expression. Anticancer Res 2005; 25: 79-83.

22 Hanahan D, Folkman J. Patterns and emerging mechanisms of the angiogenic switch during tumorigenesis. Cell 1996; 86: 353-64.

23 Stupp R, Hegi ME, Gorlia T, Erridge SC, Perry J, Hong YK, et al. Cilengitide combined with standard treatment for patients with newly diagnosed glioblastoma with methylated MGMT promoter (CENTRIC EORTC 26071-22072 study): a multicentre, randomised, open-label, phase 3 trial. Lancet Oncol 2014; 15: 1100-8.

24 Winter PM, Caruthers SD, Kassner A, Harris TD, Chinen LK, Allen $\mathrm{JS}$, et al. Molecular imaging of angiogenesis in nascent Vx-2 rabbit tumors using a novel alpha(nu)beta3-targeted nanoparticle and 1.5 tesla magnetic resonance imaging. Cancer Res 2003; 63: 5838-43.

25 Sipkins DA, Cheresh DA, Kazemi MR, Nevin LM, Bednarski MD, Li $\mathrm{KC}$. Detection of tumor angiogenesis in vivo by alphaVbeta3-targeted magnetic resonance imaging. Nat Med 1998; 4: 623-6.

26 Hu G, Lijowski M, Zhang H, Partlow KC, Caruthers SD, Kiefer G, et al. Imaging of $\mathrm{Vx}$-2 rabbit tumors with alpha(nu)beta3-integrin-targeted 111In nanoparticles. Int J Cancer 2007; 120: 1951-7.

27 Hood JD, Bednarski M, Frausto R, Guccione S, Reisfeld RA, Xiang R, et al. Tumor regression by targeted gene delivery to the neovasculature. Science 2002; 296: 2404-7.

28 Pastorino F, Brignole C, Marimpietri D, Cilli M, Gambini C, Ribatti D, et al. Vascular damage and anti-angiogenic effects of tumor vesseltargeted liposomal chemotherapy. Cancer Res 2003; 63: 7400-9.

29 Schiffelers RM, Koning GA, ten Hagen TL, Fens MH, Schraa AJ, Janssen AP, et al. Anti-tumor efficacy of tumor vasculature-targeted liposomal doxorubicin. J Control Release 2003; 91: 115-22.

30 Mundra V, Li W, Mahato RI. Nanoparticle-mediated drug delivery for treating melanoma. Nanomedicine (Lond) 2015; 10: 2613-33.

31 Danhier F, Le Breton A, Preat V. RGD-based strategies to target alpha(v) beta(3) integrin in cancer therapy and diagnosis. Mol Pharm 2012; 9: 2961-73.

32 Shuhendler AJ, Prasad P, Leung M, Rauth AM, Dacosta RS, Wu XY. A novel solid lipid nanoparticle formulation for active targeting to tumor alpha(v) beta(3) integrin receptors reveals cyclic RGD as a doubleedged sword. Adv Healthc Mater 2012; 1: 600-8.

33 Shan D, Li J, Cai P, Prasad P, Liu F, Rauth AM, et al. RGD-conjugated solid lipid nanoparticles inhibit adhesion and invasion of alphavbeta3 integrin-overexpressing breast cancer cells. Drug Deliv Transl Res 2015; 5: 15-26.

34 Bauer K, Mierke C, Behrens J. Expression profiling reveals genes associated with transendothelial migration of tumor cells: a functional role for alphavbeta3 integrin. Int J Cancer 2007; 121: 1910-8.

35 Shuhendler AJ, Cheung RY, Manias J, Connor A, Rauth AM, Wu $\mathrm{XY}$. A novel doxorubicin-mitomycin C co-encapsulated nanoparticle formulation exhibits anti-cancer synergy in multidrug resistant human breast cancer cells. Breast Cancer Res Treat 2010; 119: 255-69.

36 Shuhendler AJ, O'Brien PJ, Rauth AM, Wu XY. On the synergistic effect of doxorubicin and mitomycin $C$ against breast cancer cells. Drug Metabol Drug Interact 2007; 22: 201-33.

37 Prasad P, Cheng J, Shuhendler AJ, Rauth AM, Wu XY. A novel nanoparticle formulation overcoming multiple multidrug efflux pumps in human breast cancer. Drug Deliv Transl Res 2012; 2: 95-105.

38 Zhang RX, Cai P, Zhang T, Chen K, Li J, Cheng J, et al. Polymer-lipid hybrid nanoparticles synchronize pharmacokinetics of co-encapsulated doxorubicin-mitomycin $\mathrm{C}$ and enable their spatiotemporal codelivery and local bioavailability in breast tumor. Nanomedicine 2016; 12: 1279-90.

39 Shuhendler AJ, Prasad P, Zhang RX, Amini MA, Sun M, Liu PP, et al. Synergistic nanoparticulate drug combination overcomes multidrug resistance, increases efficacy, and reduces cardiotoxicity in a nonimmunocompromised breast tumor model. Mol Pharm 2014; 11: 2659-74.

40 Cheung RY, Rauth AM, Yu Wu X. In vivo efficacy and toxicity of intratumorally delivered mitomycin $\mathrm{C}$ and its combination with doxorubicin using microsphere formulations. Anticancer Drugs 2005; 16: 423-33.

41 Prasad P, Shuhendler A, Cai P, Rauth AM, Wu XY. Doxorubicin and mitomycin $C$ co-loaded polymer-lipid hybrid nanoparticles inhibit growth of sensitive and multidrug resistant human mammary tumor xenografts. Cancer Lett 2013; 334: 263-73.

42 Zhang RX, Wong HL, Xue HY, Eoh JY, Wu XY. Nanomedicine of synergistic drug combinations for cancer therapy-Strategies and perspectives. J Control Release 2016; 240: 489-503.

43 Zhang RX, Ahmed T, Li LY, Li J, Abbasi AZ, Wu XY. Design of nanocarriers for nanoscale drug delivery to enhance cancer treatment using hybrid polymer and lipid building blocks. Nanoscale 2017; DOI: 10.1039/C6NR08486A

44 Audeh MW. Novel treatment strategies in triple-negative breast cancer: specific role of poly(adenosine diphosphate-ribose) polymerase inhibition. Pharmgenomics Pers Med 2014; 7: 307-16.

45 Engebraaten O, Vollan HKM, Borresen-Dale AL. Triple-negative breast cancer and the need for new therapeutic targets. Am J Pathol 2013; 183: 1064-74.

46 Palma G, Frasci G, Chirico A, Esposito E, Siani C, Saturnino C, et al. Triple negative breast cancer: looking for the missing link between biology and treatments. Oncotarget 2015; 6: 26560-74.

47 Muller PA, Vousden KH. Mutant p53 in cancer: new functions and therapeutic opportunities. Cancer Cell 2014; 25: 304-17.

48 Marino N, Woditschka S, Reed LT, Nakayama J, Mayer M, Wetzel M, et al. Breast cancer metastasis: issues for the personalization of its prevention and treatment. Am J Pathol 2013; 183: 1084v95.

49 Jenkins DE, Hornig YS, Oei Y, Dusich J, Purchio T. Bioluminescent human breast cancer cell lines that permit rapid and sensitive in vivo detection of mammary tumors and multiple metastases in immune deficient mice. Breast Cancer Res 2005; 7: R444-54.

50 Khanna C, Hunter K. Modeling metastasis in vivo. Carcinogenesis 2005; 26: 513-23.

51 Smith RE, MacQuarrie R. A sensitive fluorometric method for the determination of arginine using 9,10-phenanthrenequinone. Anal Biochem 1978; 90: 246-55.

52 Chou TC. Theoretical basis, experimental design, and computerized simulation of synergism and antagonism in drug combination studies. 
Pharmacol Rev 2006; 58: 621-81.

53 Blunt T, Finnie NJ, Taccioli GE, Smith GC, Demengeot J, Gottlieb TM, et al. Defective DNA-dependent protein kinase activity is linked to $V(D)$ J recombination and DNA repair defects associated with the murine scid mutation. Cell 1995; 80: 813-23.

54 Zhou Y, He C, Chen K, Ni J, Cai Y, Guo X, Wu XY. A new method for evaluating actual drug release kinetics of nanoparticls inside dialysis devices via numerical deconvolution. J Control Release 2016; 243: 11-20.

55 Tzvetkova-Chevolleau T, Stephanou A, Fuard D, Ohayon J, Schiavone $\mathrm{P}$, Tracqui $\mathrm{P}$. The motility of normal and cancer cells in response to the combined influence of the substrate rigidity and anisotropic microstructure. Biomaterials 2008; 29: 1541-51.

56 Schuler M, Owen GR, Hamilton DW, de Wild M, Textor M, Brunette $\mathrm{DM}$, et al. Biomimetic modification of titanium dental implant model surfaces using the RGDSP-peptide sequence: a cell morphology study. Biomaterials 2006; 27: 4003-15.

57 Albanese A, Tang PS, Chan WC. The effect of nanoparticle size, shape, and surface chemistry on biological systems. Annu Rev Biomed Eng 2012; 14: 1-16.

58 Williams SS, Alosco TR, Mayhew E, Lasic DD, Martin FJ, Bankert RB. Arrest of human lung tumor xenograft growth in severe combined immunodeficient mice using doxorubicin encapsulated in sterically stabilized liposomes. Cancer Res 1993; 53: 3964-7.

59 Jokinen MP, Lieuallen WG, Boyle MC, Johnson CL, Malarkey DE, Nyska A. Morphologic aspects of rodent cardiotoxicity in a retrospective evaluation of national toxicology program studies. Toxicol Pathol 2011; 39: 850-60.

60 Babuin L, Jaffe AS. Troponin: the biomarker of choice for the detection of cardiac injury. CMAJ 2005; 173: 1191-202.
61 Jenkins DE, Oei Y, Hornig YS, Yu SF, Dusich J, Purchio T, et al. Bioluminescent imaging $(B L I)$ to improve and refine traditional murine models of tumor growth and metastasis. Clin Exp Metastasis 2003; 20: 733-44.

62 Juweid M, Neumann R, Paik C, Perez-Bacete MJ, Sato J, van Osdol W, et al. Micropharmacology of monoclonal antibodies in solid tumors: direct experimental evidence for a binding site barrier. Cancer Res 1992; 52: 5144-53.

63 Zhang L, Yu D, Hicklin DJ, Hannay JA, Ellis LM, Pollock RE. Combined anti-fetal liver kinase 1 monoclonal antibody and continuous low-dose doxorubicin inhibits angiogenesis and growth of human soft tissue sarcoma xenografts by induction of endothelial cell apoptosis. Cancer Res 2002; 62: 2034-42.

64 Lorenzo E, Ruiz-Ruiz C, Quesada AJ, Hernandez G, Rodriguez A, Lopez-Rivas A, et al. Doxorubicin induces apoptosis and CD95 gene expression in human primary endothelial cells through a p53dependent mechanism. J Biol Chem 2002; 277: 10883-92.

65 Bellou S, Pentheroudakis G, Murphy C, Fotsis T. Anti-angiogenesis in cancer therapy: Hercules and hydra. Cancer Lett 2013; 338: 219-28.

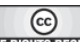

This work is licensed under the Creative Commons Attribution-NonCommercial-No Derivative Works 3.0 Unported License. To view a copy of this license, visit http://creativecommons.org/licenses/ by-nc-nd/3.0/

(C) The Author(s) 2017 